\title{
Role models, society and expectations: a subtle and challenging route
}

\section{LISA O'CONNOR}

Most of the topics discussed so far relate to the involvement of women from university level up. We are missing the most important point. For the majority of the population, decisions such as what to do with your life, such as becoming a Nobel winner or having a family, are made at a very early age. Once someone has decided to commit to an area, whether they will stick with it will depend on the individual and their circumstances. Sure there are obstacles, but that is life.

Women do have to 'out prove' their male counterparts, but what can you do? You can pressure organisations to place non-sexist people in decision making roles, but office politics will always exist. An unfortunate aspect of life. What we must push forward to is an age where women are not a minority, and there is no such thing as a 'non-traditional' area. Suggestions of female only scholarships and positions do more harm than good. No one said the female revolution was going to be easy. We need to be brave and conquer the challenges, if only to say to our grand-daughters, "You've got no appreciation for how hard it was in our day".

The solution to getting more women into "non-traditional" fields is unfortunately a more subtle and challenging area than any single institute or group may be able to tackle. It is due to social expectations, and begins from the day a baby girl or a baby boy is born into a family. I do not consider my parents archaic but in retrospect it is surprising that they put so much hope into only one child - the boy - and didn't expect anything much out of their two girls.

Society brings up children by subtly conditioning them to a way of thinking, and establishing in them life expectations. As a child no one asked me what I thought, or showed me things. For example: "see how that bridge can stand with such a large span?", "you should spend the holidays with your uncle the computer scientist", "tell me what you learnt today", "what type of car is that?", "why do you think the water is green here but blue over there?". It wasn't until I started bringing home fancy report cards, that it was noticed that I might have a "career option". But it's not just the parents. Often a teacher can have a profound impact on a child's life, and their personal views on the place of males and females in society would obviously pervade their approach to educating students on life, whether they realised it or not.

One of the biggest socialisers is television. Role model? What was that? On any television show, the females young and old were praised for having tame ambitions, and encouraged to go out and seek a male provider. Unfortunately things have not changed at all. Certainly, there are more shows aimed at women, but any professional female character is limited to a career in medicine, law, television, fashion or tourism (all of which women have a good representation in real life). Will someone please explain to me what the problem is with having one or two token female scientist/engineer roles in a sitcom? If we - parents, siblings, friends, teachers, television, magazines, community groups, politicians, society - reward pretty slim girls, with smart one liners and a trail of boyfriends, with praise and admiration, why on earth would a girl want to be anything else?

The focus should be on primary schools - develop the confidence in little girls, to question the wonderful thing that life is, and ask, "Why does that happen?" Or, if you want a controversial answer, pay David E. Kelly to write you a television series with role models in the areas of science, engineering, and trades, (but please get rid of the Ally MacBeals). Look what LA Law did for 
lawyers, and what ER did for medicine. Unconventional for academia, but extremely effective.

\section{Lisa O'Connor}

PO Box 5350

Kalgoorlie, Australia

lisa.oconnor@bigpond.com

Nature@ Macmillan Publishers Ltd 1999 Registered No. 785998 England. 